\title{
Antidiabetic Potential and HPTLC Fingerprinting of Schleichera oleosa (Lour) Oken
}

\author{
Shambaditya Goswami ${ }^{1,{ }^{*}}$, Ravindra Pal Singh ${ }^{2}$
}

\section{Shambaditya Goswami ${ }^{1}{ }^{1,}$, Ravindra Pal Singh ${ }^{2}$}

${ }^{1}$ Research Scholar, Suresh Gyan Vihar University, Jaipur, Rajasthan, INDIA. ${ }^{2}$ Faculty of Pharmacy, Suresh Gyan Vihar University, Jaipur, Rajasthan, INDIA.

Correspondence

Mr. Shambaditya Goswami

Institute of Technology and Management, GIDA, Gorakhpur, Uttar Pradesh-273209, INDIA.

Phone no : +91-9450513480

E-mail: shambampharma@gmail.com

\section{History}

- Submission Date: 30-09-2018;

- Review completed: 12-12-2018;

- Accepted Date: 21-01-2019

DOI : 10.5530/pj.2019.11.74

Article Available online http://www.phcogj.com/v11/i3

\section{Copyright}

(C) 2019 Pharmacognosy Journal. This is an open-access article distributed under the terms of the Creative Commons Attribution 4.0 International license.

\begin{abstract}
Introduction: Schleichera oleosa (Lour) Oken., also known as Lac tree, is a traditional plant used to treat different ailments since ancient time. The folkloric use of this plant as hypoglycemics is still un-revealed scientifically. So, the present study includes the in-vivo evaluation of hypoglycemic activity with HPTLC fingerprinting, qualitative and quantitative phytochemical screening of the extracts of the plant. Methods: Ethanolic extract of the plant (SOE) was subjected for phytochemical screening and HPTLC finger printing (using CAMAG LINOMAT 5 instrument). For the evaluation of hypoglycemic activity Streptozotocin (STZ) induced diabetic rats were treated with glibenclamide $(0.5 \mathrm{mg} / \mathrm{kg}$ body weight) and ethanolic extract $(100 \mathrm{mg} / \mathrm{kg}$ and $200 \mathrm{mg} / \mathrm{kg}$ body weight) of the plant. Acute and chronic studies were performed for the evaluation of blood glucose levels. Results: The presence of alkaloids, tannins, phenolics and flavonoids were confirmed in the preliminary phytochemical screening. Quantitative screening of total tannins $(6.15 \pm 4.20)$, total flavonoids $(25.13 \pm 3.21)$ and total phenolic compounds $(48.09 \pm 2.58)$ were reported. HPTLC fingerprinting analysis of SOE affirmed the presence of quercetin. Conclusion: The positive outcome was observed in the results of hypoglycemic activity, as all the treatments significantly decreased blood glucose level. During the study, SOE and glibenclamide maintained the body weight of the rats while diabetic control reduced the body weight by $11.33 \%$. In support of its traditional use Schleichera oleosa (Lour) Oken. was proved to be a potent antidiabetic herbal plant.

Key words: Schleichera oleosa (Lour) Oken, Hypoglycemic, HPTLC, Quercetin.
\end{abstract}

\section{INTRODUCTION}

Hyperglycemia is a result of high blood glucose in plasma and diabetes is the authentication mark of it. ${ }^{1}$ Diabetes mellitus is a group of metabolic disorder mainly characterized by high blood glucose level in the blood (hyperglycemia), kidney (glycosuria), hyperlipidemia and ketonaemia. Type II diabetes also called as maturity onset diabetes mellitus, is caused due to abnormal function of glucoreceptors of $\beta$-cells of the pancreatic islet of Langerhans resulting in insufficient production of insulin. ${ }^{2}$ The global scenario of diabetes is very alarming, as the counts of diabetic affected people will be more than 640 million by 2040. In India, the management of diabetes is very challenging mainly because of lacking public awareness and expensive cost of medications. ${ }^{3}$

Diabetic-kidney disease, liver diseases and coronary artery diseases are the common and severe complications associated with diabetes. ${ }^{4}$ The oral hypoglycemic drugs have potential adverse effects like low blood sugar, obesity, gastrointestinal disturbances, dizziness etc. ${ }^{5}$ The choice of medicinal plants as an alternative approach for the management of diabetes is helpful to get rid of the diabetic complications. ${ }^{6}$
Schleichera oleosa (Lour) Oken., belongs to Sapindaceae family, is a medicinal plant having the plethora of ailment treating properties. The plant possesses several biological effects like antiulcer, anticancer, antimicrobial activities. Traditionally the plant is used as an antidiabetic.?

Though the in-vitro study of the antidiabetic activity of Schleichera oleosa (Lour) Oken. has been reported recently by evaluating alpha-amylase inhibition, ${ }^{8}$ scientific in-vivo evaluation has not been done yet.

The present research deals with the in-vivo evaluation of hypoglycemic activity on streptozotocin induced diabetic rats and the High Performance Thin Layer Chromatography (HPTLC)-fingerprinting analysis of Schleichera oleosa (Lour) Oken.

\section{MATERIALS AND METHODS}

\section{Collection and authentication of the plant}

The plant Schleichera oleosa (Lour) Oken., was collected from Maharajganj, Uttar Pradesh, India and the leaves of the plant were authenticated by Indian Council of Agricultural Research (ICAR)Kamla Nehru Krishi Vigyan Kendra, Sultanpur, Uttar Pradesh, India (Specimen No. 02/2017).
Cite this article: Goswami S, Singh RP. Antidiabetic Potential and HPTLC Fingerprinting of Schleichera oleosa (Lour) Oken. Pharmacog J. 2019;11(3):469-74. 


\section{Crude extracts preparation}

The shade-dried cleaned leaves were powdered in grinder mixer, passed through sieve no. 40. The crude ethanolic (ethanol 95.5\% v/v) extract of the powder was prepared by hot percolation process using Soxhlet apparatus at $70^{\circ}-80^{\circ} \mathrm{C}$ for $32 \mathrm{~h}$ followed by distillation and drying. The crude extracts (SOE) were kept at desiccators for further experiments.

\section{Qualitative and quantitative Phytochemical screening}

The qualitative identification of phytoconstituents of the ethanolic extract for alkaloids, tannins, flavonoids and phenolic compounds were performed by following standard methods. For alkaloids Mayer's, Dragendroff's, Hager's and Wagner's tests were performed. Chloride test and Vaniline tests were performed to identify tannins. Flavonoids were identified by the treatment of extract with aqueous sodium hydroxide, concentrated sulphuric acid and Shinoda's test, whereas, ferric chloride, lead acetate and bromine water were used to assure the presence of phenolics. $^{9}$

The quantitative estimations of tannins (Folin-Ciocalteau assay), ${ }^{10}$ flavonoids (Aluminium chloride colorimetric assay) ${ }^{11}$ phenolic compounds (Folin-Ciocalteau reagent-15\% sodium carbonate assay) ${ }^{12}$ were examined by the standard methods with minor modifications in triplicates and the results were represented as mg of Tannic acid, Quercetin and Gallic acid equivalents per gm dry weight respectively.

\section{HPTLC fingerprinting}

The study of HPTLC fingerprinting was done according to the standard procedures. ${ }^{13-14}$ The analysis was done by CAMAG LINOMAT 5 instrument (Camag; Muttenz, Switzerland), operated by WINCATS software. The ethanolic extract of Schleichera oleosa (Lour) Oken. was dissolved with HPTLC grade ethanol (100 $\mathrm{mg}$ in $1 \mathrm{ml}$ ) followed by centrifugation. Quercetin was taken as standard. Sample solution and standard solution (each of $2 \mu \mathrm{l}$ ) were sprayed on Silica gel $60 \mathrm{~F}_{254}$ TLC plate as bands of $5 \mathrm{~mm}$ length $10 \mathrm{~mm}$ from the bottom edge, $10 \mathrm{~mm}$ from the side edge and $6 \mathrm{~mm}$ apart using $100 \mu \mathrm{l}$ Hamilton syringe. Saturation of the chamber was done with Toluene: Ethyl acetate: Formic acid (13:11:2), as the mobile phase for $25 \mathrm{~min}$ at room temperature. The chromatogram was developed by following ascending technique in CAMAG twin trough developer from the point of sample application to approximately $80 \mathrm{~mm}$ solvent front in given mobile phase followed by the drying of the plates in hot air to remove the solvent. The plates were kept in CAMAG REPROSTAR 3 (photo-documentation chamber). The images were taken at the different wavelength of $254 \mathrm{~nm}$ and $366 \mathrm{~nm}$. After derivatization, the plates were fixed in CAMAG TLC SCANNER 3 for densitometric scanning, done at $500 \mathrm{~nm}$. All the data like peak height, peak area, $R_{f}$ values, peak densitogram were denoted.

\section{Hypoglycemic activity}

Experimental animals

For the experimental design healthy albino Wistar rats ( $160 \pm 20 \mathrm{~g}$ of body weight) were selected and the animals were kept in the animal house at the standard condition with commercial pellet diet and water. The animals were kept for 1 week before commencement of experiments and all the experiments were carried out by the approval of Institutional Animal Ethics Committee (IEAC) of Suresh Gyan Vihar University (Approval No: SGVU/PH/IAEC/2017/01).

\section{Diabetes induction}

Healthy selected rats were fasted overnight before induction of diabetes through Streptozotocin (STZ). Intraperitoneal injection of STZ at $50 \mathrm{mg} / \mathrm{kg}$ body weight in $0.1 \mathrm{M}$ sodium citrate buffer was administered. Induction was confirmed after $48 \mathrm{~h}$ of administration. $>200 \mathrm{mg} / \mathrm{DL}$ value of fasting glucose level was confirmed as diabetic animals and screened for the further experiments. Glibenclamide (GLI) was used as standard drug.
The dose of the plant extract was selected by following the acute toxicity study. ${ }^{15}$

\section{Experimental design}

The following five diabetic groups $(n=5)$ were designed for the activity: Group I - Non-diabetic control (NC)

Group II - Diabetic control (DC)

Group III - Diabetic rats administered with GLI $(0.5 \mathrm{mg} / \mathrm{kg}$ body weight) (DC+GLI)

Group IV - Diabetic rats administered with SOE (DC+SOE) in the dose of $100 \mathrm{mg} / \mathrm{kg}$

Group V - Diabetic rats administered with SOE (DC+SOE) in the dose of $200 \mathrm{mg} / \mathrm{kg}$

Acute study

After the administration of GLI and SOE, the blood glucose level was noted at $0,2,4,6$ and $24 \mathrm{~h}$.

\section{Chronic study}

After daily dosing of GLI and SOE plant extracts, the body glucose of the rats was monitored for 28 days at the interval of $0,7,14,21$ and 28 days.

\section{Blood glucose estimation}

The blood samples were collected from all the rats through tail-vein and blood glucose levels were measured (in $\mathrm{mg} / \mathrm{dL}$ ) instantly by using glucometer (Accu-chek, Roche Diagnostic, Mannheim, Germany). ${ }^{16}$

\section{Body weight estimation}

Body weight of the rats was recorded before (at 0 days) and after (at 28 days) of the study. The percentage change of the body weight was recorded and tabulated.

\section{Statistical analysis}

The results were expressed in \pm SEM $(n=5)$ and the comparison between the groups were determined followed by Tukey's multiple comparisons test, ${ }^{\star} p<0.01,{ }^{*} p<0.001$ were considered as significant. All the graphs were drawn in GraphPad Prism 7.4 software.

\section{RESULTS}

\section{Qualitative and quantitative phytochemical screening}

The ethanolic extract showed the presence of alkaloids, tannins, flavonoids and phenolic compounds, tabulated in Table 1. Quantitative estimations of total tannin, total flavonoids and total phenols were reported in Table 2 as $6.15 \pm 4.20 \mathrm{mg}$ TAEg, $25.13 \pm 3.21 \mathrm{mg}$ QEg, $48.09 \pm 2.58 \mathrm{mg}$ GAEg dry weight respectively.

\section{HPTLC fingerprinting for Quercetin}

HPTLC fingerprinting of SOE was performed with the suitable solvent system and visualized under UV $254 \mathrm{~nm}$ and $366 \mathrm{~nm}$. The chromatogram and densitogram were given in Figure 1 and 2. The densitogram evidenced 12 bands of $R_{f}$ values of $0.10,0.23,0.46,0.49,0.57,0.62,0.69$, $0.74,0.77,0.84,0.93$ and 0.99 , in which fourth one confirmed as quercetin while compared to standard (Figure 3 ). The $R_{f}$ values, peak areas, height has been tabulated in detail in Table 3.

\section{Hypoglycemic activity}

Acute and chronic studies were performed to assess the hyperglycemic effect of SOE in two different doses which exhibited significant activity. To predict the acute effect, the blood glucose levels at the different time interval $(0,2,4,6$ and $24 \mathrm{~h})$ were measured and reported in Figure 4. The reduction of blood glucose levels of glibenclamide on diabetic rats were 
Table 1: Phytochemical screening of SOE.

\begin{tabular}{cc}
\hline Phytochemicals & Ethanolic extract of leaves \\
\hline Alkaloids & +-++ \\
Tannins & ++ \\
Phenolic compounds & +++ \\
Flavonoids & +++ \\
\hline
\end{tabular}

(+ indicates 'Presence' and - indicates 'Absence' of phytochemicals)

Table 2: Quantitative phytochemical estimations of SOE.

\begin{tabular}{cc}
\hline Estimations & SOE \\
\hline Total Tannins (mg TAEg DW) & $6.15 \pm 4.20$ \\
Total Flavonoids (mg QEg DW) & $25.13 \pm 3.21$ \\
Total Phenols (mg GAEg DW) & $48.09 \pm 2.58$ \\
\hline
\end{tabular}

(All Values represent Mean \pm SEM; All the samples were analyzed in triplicate)

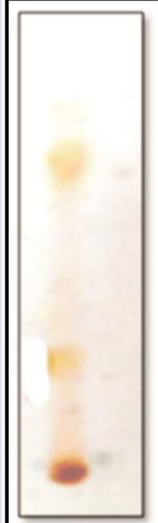

(a)

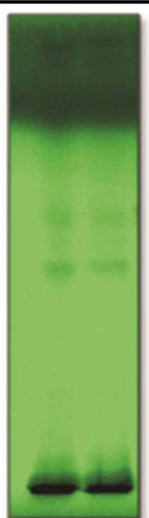

(b)

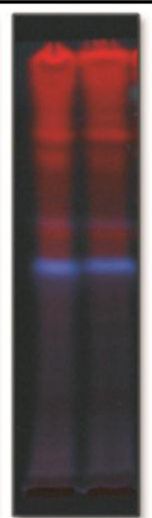

(c)

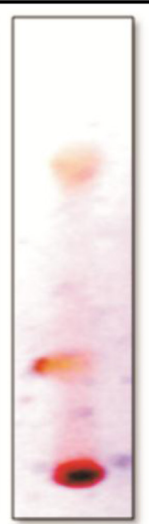

(d)

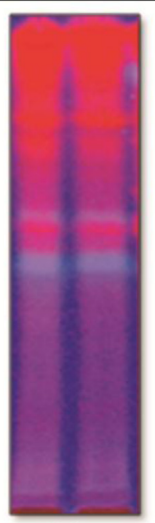

(e)
Figure 1: HPTLC chromatogram profile of SOE.

Before derivatization (a) Visible light, (b) UV $254 \mathrm{~nm}$, (c) UV $366 \mathrm{~nm}$; After derivatization (d) Visible light, (e) UV $366 \mathrm{~nm}$.

highest (21.5\%) than the higher dose of SOE (19.16\%) and the lower dose of SOE (15.59\%) in $24 \mathrm{~h}$.

For the long-term effect of the extract on hyperglycemia, the chronic study was conducted and the blood glucose levels were reported after the study of 28 days at 7 days interval (Figure 5). Among the two extracts, high dose of SOE $(200 \mathrm{mg} / \mathrm{kg})$ lowered the blood glucose more significantly (from $287 \pm 5.10$ to $140 \pm 5.70 \mathrm{mg} / \mathrm{dl}$ ) than low dose of SOE $(100 \mathrm{mg} / \mathrm{kg}$ ) (from $295 \pm 4.70$ to $180 \pm 3.54 \mathrm{mg} / \mathrm{dl}$ ); however, the effect of glibenclamide was greatest among all (from $293 \pm 4.20$ to $129 \pm 5.10 \mathrm{mg} / \mathrm{dl}$ ).

The preventing effect of body weight loss of SOE was conducted at first day and $28^{\text {th }}$ day after the study (Table 4$)$. Glibenclamide, SOE $(200 \mathrm{mg} / \mathrm{kg})$ and SOE $(100 \mathrm{mg} / \mathrm{kg})$ showed $7.5,10.37$ and $11.39 \%$ increase in body weight, whereas, diabetic control decreases the body weight by $11.33 \%$ (Figure 6).

\section{DISCUSSION}

Binding of insulin at alpha-subunit of insulin receptor activates tyrosine kinase activity at beta-subunit of the receptor followed by cascade of phosphorylation and dephosphorylation reactions which causes the activation of secondary messengers, MAP (Mitogen-Activated Protein)

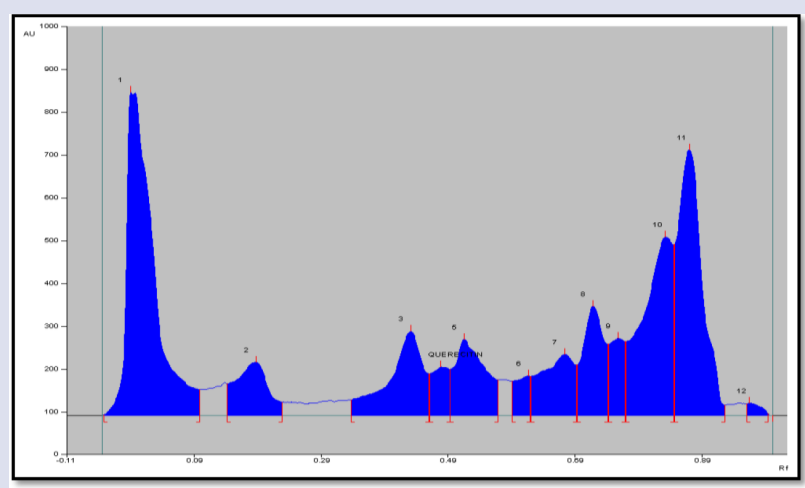

Figure 2: HPTLC densitogram for SOE at $254 \mathrm{~nm}$.

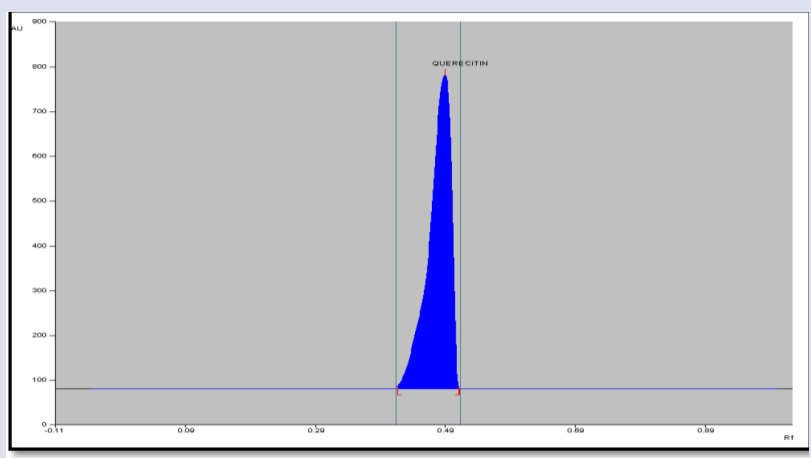

Figure 3: HPTLC densitogram for Quercetin standard.

Table 3: HPTLC profile of SOE with Rf, height and area.

\begin{tabular}{cccccc}
\hline Track & Peak & Rf & $\begin{array}{c}\text { Max Height } \\
(\mathrm{AU})\end{array}$ & $\begin{array}{c}\text { Area } \\
(\mathrm{AU})\end{array}$ & Assigned substances \\
\hline SOE & 1 & 0.10 & 755.8 & 32595.7 & Unknown 1 \\
SOE & 2 & 0.23 & 124.6 & 6441.9 & Unknown 2 \\
SOE & 3 & 0.46 & 196.8 & 10512.8 & Unknown 3 \\
SOE & 4 & 0.49 & 113.8 & 3115.2 & Flavonoid \\
& & & & & 1 (Quercetin) \\
SOE & 5 & 0.57 & 177.6 & 8585.6 & Unknown 4 \\
SOE & 6 & 0.62 & 93.1 & 2248.6 & Unknown 5 \\
SOE & 7 & 0.69 & 143.2 & 7463.1 & Unknown 6 \\
SOE & 8 & 0.74 & 255.4 & 8553.6 & Unknown 7 \\
SOE & 9 & 0.77 & 180.4 & 4025.3 & Unknown 8 \\
SOE & 10 & 0.84 & 416.6 & 19885.3 & Unknown 9 \\
SOE & 11 & 0.93 & 620.7 & 24028.5 & Unknown 10 \\
SOE & 12 & 0.99 & 28.7 & 660.7 & Unknown 11 \\
STD & 13 & 0.51 & 700.4 & 24011.3 & Quercetin Standard \\
\hline
\end{tabular}




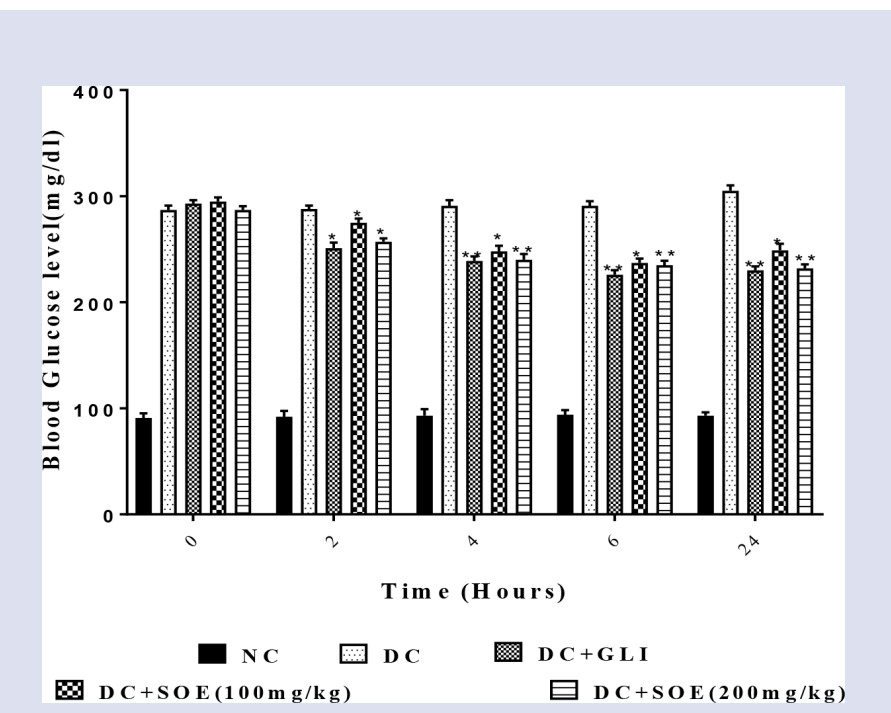

Figure 4: Acute hypoglycemic effect of SOE.

All values were expressed as \pm Standard error of the mean $(n=5)$, followed by Tukey's multiple comparisons test, * $p<0.01,{ }^{* *} p<0.001$ were considered as significant.

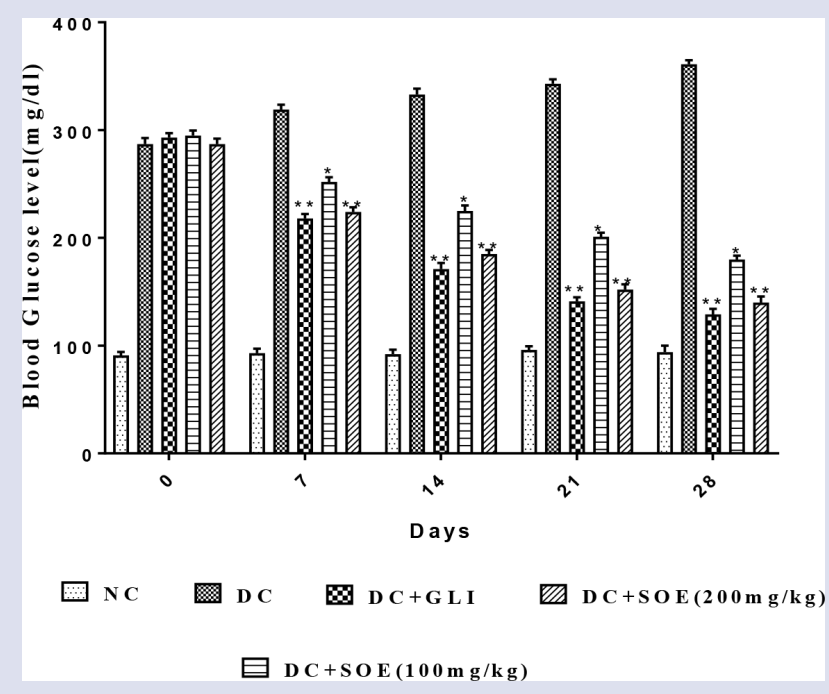

Figure 5: Chronic hypoglycemic effect of SOE.

All values were expressed as \pm Standard error of the mean $(n=5)$, followed by Tukey's multiple comparisons test, ${ }^{*} p<0.01,{ }^{* *} p<0.001$ were considered as significant.

kinase and Glucose Transporters (GLUT) to maintain the normal blood glucose. The insufficient production of insulin fails to regulate normal blood glucose level and causes diabetes. The phytochemical screening of SOE affirmed the presence of tannins, flavonoids and phenolic compounds. Tannins increase the glucose uptake by activating GLUT-4, MAP kinase and secondary messengers like PI3K (Phosphoinositide 3-Kinase). ${ }^{17}$ Stimulation of insulin production, preventing gluconeogenesis, enhancing insulin sensitivity and glucose uptakes are the few possible mechanisms of flavonoids in the regulations of diabetes. ${ }^{18} \alpha$-amylase and a-glucosidase enzymes of the digestive tract can delay the absorption of
Table 4: Effect of SOE on body weight of STZ induced diabetic rats.

\begin{tabular}{ccc}
\hline Groups & $\begin{array}{c}\text { Body weight before the } \\
\text { study (g) }\end{array}$ & $\begin{array}{c}\text { Body weight after the } \\
\text { study (g) }\end{array}$ \\
\hline Group I & $132.4 \pm 2.4$ & $134.6 \pm 2.3$ \\
Group II & $157.1 \pm 1.7$ & $139.3 \pm 5.8$ \\
Group III & $142.5 \pm 2.7$ & $153.2 \pm 4.1$ \\
Group IV & $146.6 \pm 3.21$ & $163.3 \pm 2.7$ \\
Group V & $156.2 \pm 4.2$ & $172.4 \pm 3.4$ \\
\hline
\end{tabular}

All values were expressed as \pm Standard error of the mean $(n=5)$

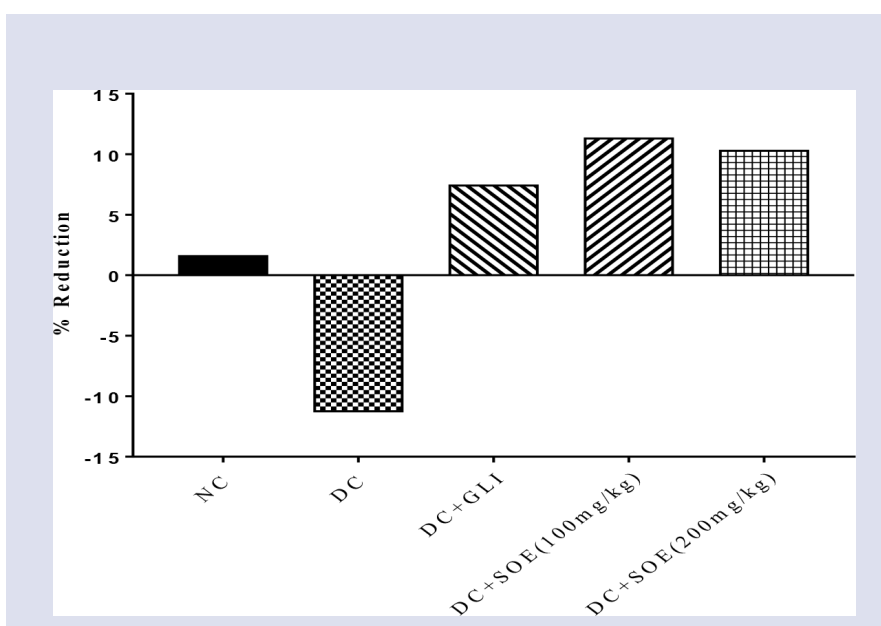

Figure 6: Effect on body weight (in percentage reduction) of SOE.

glucose, so, their inhibition by phenolic compounds helps to control the post-prandial hyperglycemia. ${ }^{19}$

HPTLC fingerprinting is an accurate and precise instrumental technique to identify the phytoconstituents and adulterants present in medicinal plants. ${ }^{20-21}$ HPTLC serves as an important highly efficacious technique to establish the appropriate quality control parameters for the herbal extracts. ${ }^{22}$ The present investigation of HPTLC fingerprinting of SOE affirmed the presence of quercetin along with twelve other compounds. Quercetin which is a part of the subclass of flavonoids groups of polyphenols, is an important aspect of research because of its versatile effect mainly on degenerative diseases by inhibiting lipid peroxidation. ${ }^{23}$ The earlier studies reported that quercetin has significant hypoglycemic effect in STZ induced rats perhaps by increasing the insulin secretions. ${ }^{24-26}$ Despite all the effective researches in synthetic chemistry for oral hypoglycemic drugs, the reliability on medicinal plants for the management of hyperglycemia is a long practice almost all over the world due to its affordability. ${ }^{27}$ The use of medicinal herbs is the important aspect of an alternative approach to manage diabetes. ${ }^{6}$ The presence of several active phytoconstituents in medicinal herbs serve a protective and therapeutic effect on diabetes mellitus by the reduction in insulin resistance, preventing glycogenolysis and gluconeogenesis. ${ }^{28}$ The present work evaluated the hypoglycemic activity of SOE in STZ induced diabetic rats and the results were significant $\left({ }^{*} p<0.01,{ }^{* *} p<0.001\right.$ were considered as significant) as compared to diabetic control. STZ, obtained from a gram-positive bacterium, is uptake by pancreatic $\beta$-cells (via GLUT-2) to destroy them by several proposed mechanisms. ${ }^{29}$ In case of acute study, the reduction of blood glucose of glibenclamide treated diabetic rats in first $6 \mathrm{~h}$ were found higher than SOE-high dose and SOE-low dose. The similar result was reported for Rhizophora mucornata in which high 
dose $(200 \mathrm{mg} / \mathrm{kg})$ of hydroalcoholic extract of the plant was found more potent than the low dose in first $6 \mathrm{~h}$ of the study. ${ }^{16}$ For the daily treatment of SOE and glibenclamide up to 28days, it was found that the higher dose of SOE (51.21\%) was more significant than SOE low dose (38.98\%) in blood glucose lowering while compared to glibenclamide (55.97\%). The similar study of the hypoglycemic effect of Kyllinga triceps plant extracts at $200 \mathrm{mg} / \mathrm{kg}$ on STZ induced rats was reported as a significant $(47.2 \%$ blood glucose reduction) than low dose. ${ }^{30}$ The result of improvement in body weight of the rats for the daily treatment of SOE was important aspect in maintaining the body weight without altering the normal health, as obesity is the important issue for the management of type- 2 diabetes. $^{31}$

\section{CONCLUSION}

In recent scientific research the alternative approach for the management of diabetes is an important exposure. The present study proved Schleichera oleosa (Lour) Oken. as a hypoglycemic agent. The presence of quercetin will help to isolate and characterize the active constituents responsible for the hypoglycemic activity and will be the future scope.

\section{ACKNOWLEDGEMENT}

The authors are gratefully acknowledged the Management and Director of Suresh Gyan Vihar University, Jaipur and Institute of Technology and Management (ITM, GIDA) for their valuable and immense support for the work by providing the necessary facilities.

\section{CONFLICT OF INTEREST}

The authors declare no conflict of interests.

\section{ABBREVIATIONS}

SOE: Ethanolic extract of Schleichera oleosa (Lour) Oken.; STZ: Streptozotocin; GLI: Glibenclamide; NC: Non-diabetic control; DC: Diabetic control.

\section{REFERENCES}

1. Tang $Y$, Long J, Liu J. Hyperglycemia-associated oxidative stress induces autophagy: involvement of the ROS-ERK/JNK-p53 pathway. Autophagy: Cancer, Other Pathologies, Inflammation, Immunity, Infection and Aging. Academic Press. 2014;105-15.

2. Alagarsamy $V$. Text book of medicinal chemistry. $2^{\text {nd }}$ ed. New Delhi: Reed Elsevier India Pvt. Ltd. 2014.

3. Unnikrishnan R, Anjana RM, Mohan V. Diabetes mellitus and its complications in India. Nat Rev Endocrinol. 2016;12(6):357-70.

4. Yaro AH, Aliyu M, Borodo SB, Nazifi AB. Antihyperglycaemic and antihyperlipidaemic activities of ethanol leaf extract of Eleusine coracana (Linn.) Gaertn. in alloxan-Induced hyperglycaemic rats. J Appl Pharm Sci. 2018;8(07):28-32.

5. Manandhar SJT, Shrestha H, Prajapati M, Karkee A, Maharjan A. Adverse effects of oral hypoglycemic agents and adherence to them among patients with type 2 diabetes mellitus in Nepal. J Lumbini Med Coll. 2017;5(1):34-40.

6. Tripathi P, Srivatava R, Pandey A, Pandey R, Goswami S. Alternative therapies useful in the management of diabetes: a systematic review. J Pharm Bioallied Sci. 2011;3(4):504-12.

7. Goswami S, Singh RP. Ayurvedic, phytochemical and pharmacological review of Schleichera oleosa (Lour.) Oken: a traditional plant with enormous biological activity. World J Pharm Res. 2017;6(10):295-309.

8. Muthukrishnan S, Sivakkumar T. In vitro studies to assess the antidiabetic potential of Schleichera oleosa (Lour) oken leaves. Asian J Pharm Clin Res. 2017;10(7).
9. Khandelwal KR. Practical pharmacognosy: techniques and experiments. $16^{\text {th }}$ ed. Nirali Prakashan. 2008.

10. Mohammed S, Manan FA. Analysis of total phenolics, tannins and flavonoids from Moringa oleifera seed extract. J Chem Pharm Res. 2015;7(1):132-5.

11. Sulaiman CT, Balachandran I. Total Phenolics and total flavonoids in selected Indian medicinal plants. Indian J Pharm Sci. 2012;74(3):258-60.

12. Pontis JA, Antonio L, Alves M, José S, Flach A. Color, phenolic and flavonoid content and antioxidant activity of honey from Roraima, Brazil. Food SciTechnol. 2014;34(1):69-73.

13. Gomathi D, Ravikumar G, Kalaiselvi M, Vidya B, Uma C. HPTLC fingerprinting analysis of Evolvulus alsinoides (L.) J Acute Med. 2012;2(3):77-82.

14. Varghese S, Narmadha R, Gomathi D, Kalaiselvi M, Devaki K. Phytochemical screening and HPTLC finger printing analysis of Citrullus lanatus (Thunb.) seed. J Acute Dis. 2013;2(2):122-6.

15. Singh J, Parasuraman S, Kathiresan S. Antioxidant and antidiabetic activities of methanolic extract of Cinnamomum cassia. Pharmacognosy Res. 2018; 10(3):237-42

16. Pandey AK, Gupta PP, Lal VK. Hypoglycemic effect of Rhizophora mucronata in streptozotocin induced diabetic rats. J Complement Integr Med. 2014;11(3):17983.

17. Kumari M, Jain S. Tannins: an antinutrient with positive effect to manage diabetes. Res J Recent Sci. 2012;1(12):70-3.

18. Vinayagam $R, X u B$. Antidiabetic properties of dietary flavonoids: a cellular mechanism review. Nutr Metab (Lond). 2015;12(60):1-20

19. Asgar MA. Anti-diabetic potential of phenolic compounds: A Review. Int J Food Prop. 2013;16(1):91-103

20. Senguttuvan J, Subramaniam P. HPTLC Fingerprints of various secondary metabolites in the traditional medicinal herb Hypochaeris radicata L. J Bot 2016:2016:1-11.

21. Attimarad M, Ahmed KKM, Aldhubaib BE, Harsha S. High-performance thin layer chromatography: A powerful analytical technique in pharmaceutical drug discovery. Pharm Methods. 2011;2(2):71.

22. Shivatare RS, Nagore DH, Nipanikar SU. 'HPTLC' an important tool in standardization of herbal medical product: A review. J Sci Innov Res. 2013;2(6):1086-96.

23. Bentz AB. A review of quercetin: chemistry, antioxidant properties and bioavailability. J Young Investig. 2009;1-14.

24. Srinivasan P, Vijayakumar S, Kothandaraman S, Palani M. Anti-diabetic activity of quercetin extracted from Phyllanthus emblica L. fruit: In silico and in vivo approaches. J Pharm Anal. 2018;8(2):109-18.

25. Vessal M, Hemmati M, Vasei M. Antidiabetic effects of quercetin in streptozocin-induced diabetic rats. Comp Biochem Physiol C Toxicol Pharmacol. 2003;135(3):357-64

26. Abdelmoaty MA, Ibrahim MA, Ahmed NS, Abdelaziz MA. Confirmatory studies on the antioxidant and antidiabetic effect of quercetin in rats. Indian $\mathrm{J}$ Clin Biochem. 2010;25(2):188-92.

27. Yakubu MT, Sunmonu TO, Lewu FB, Ashafa AOT, Olorunniji FJ, Eddouks M Medicinal plants used in the management of diabetes mellitus 2015. Evid Based Complement Alternat Med. 2015;2015:1-2.

28. Farzaei F, Morovati MR, Farjadmand F, Farzaei MH. A mechanistic review on medicinal plants used for diabetes mellitus in traditional Persian medicine. $J$ Evid Based Integr Med. 2017;22(4):944-55

29. Goud BJ, Dwarakanath V, Chikka SBK. Streptozotocin - a diabetogenic agent in animal models. Int J Pharm Pharm Res. 2015;3(1):253-69.

30. Lal V, Gupta P, Pandey A. Hypoglycemic effect of Kyllinga triceps in STZ induced diabetic rats. J Diabetes Metab. 2012;03(06):1-3.

31. Beebe C. Body weight issues in preventing and treating type 2 diabetes. Diabetes Spectr. 2003;16(4):261-6. 
GRAPHICAL ABSTRACT

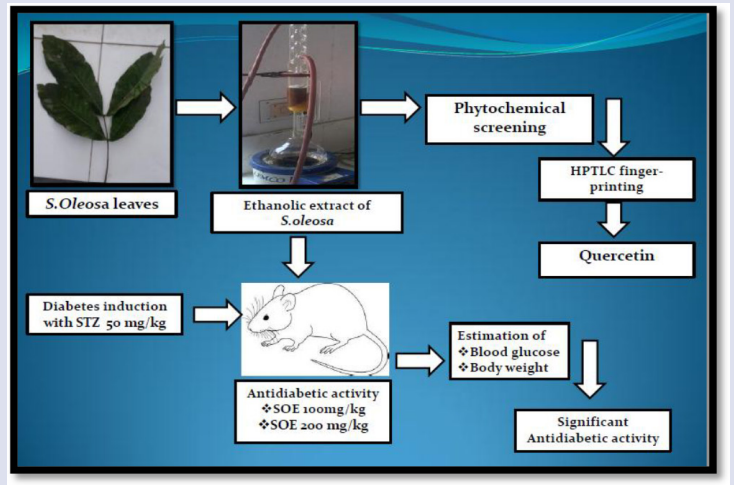

\section{SUMMARY}

- The qualitative and quantitative phytochemical screening for the ethanolic extract of Schleichera oleosa (Lour) Oken was performed. Presence of alkaloids, tannins, phenolic compounds and flavonoids were reported.

- HPTLC fingerprinting was performed and presence of quercetin was assured

- Hypoglycemic activity was performed with two different doses.

- Significant outcome was noted.

\section{ABOUT AUTHORS}

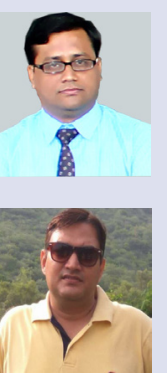

Shambaditya Goswami: He is a research scholar of Suresh Gyan Vihar University, Jaipur. His area of interest is phytochemistry and synthetic chemistry.

Dr. Ravindra Pal Singh: He is a renowned researcher in Pharmaceutical Science field. He is having 14 years of vast academic experience. His areas of interests are floating drug delivery system and phytochemistry. 